\title{
Empirical Analysis on Dishonesty Behaviors of Main Bodies In Construction Ineffective Bidding
}

\author{
Xiaoli Wei ${ }^{1, a}$, Yanfeng Xing ${ }^{2, b}$ and Yihua Wei ${ }^{1, c}$ \\ ${ }^{1}$ Dept. of Management, Shanghai University, Shanghai 200072, China; \\ 2 Shanghai University of Engineering Science, Shanghai 201620, China. \\ aelisawei@163.com, byf2001721@163.com, cweiyh2001@aliyun.com
}

Keywords: Ineffective tendering, dishonesty of bidding main bodies; bidding rigging; game theory model.

\begin{abstract}
In the process of engineering construction, due to various subjective or objective reasons, the bidding activities can not play the effectiveness of optimal deal and allocation of resources, so as to make the bidding become the format, is called the ineffective tendering in this paper. For the most prominent dishonesty behaviors of main bodies in construction ineffective bidding, this paper makes the empirical analysis through the real cases and analyzes the dishonesty behaviors and motivations of the main subjects including the tenderee, bidders, supervising levels and evaluation parties. For the most serious and prominent problem of bidding rigging, establish the game theory model. Finally, this article concludes that establishing the credit evaluation mechanism, strengthening the information disclosure, introducing bidding supervision and report incentive mechanism can help to reduce the dishonesty behaviors. From long term view, it also help to weaken the preference of bidding dishonesty and change the social atmosphere so that bidding system can play better for the role of effective allocation of social resources.
\end{abstract}

\section{Introduction}

Tendering and bidding has a wide range of applications in the transaction of current government procurement activities and large-scale construction projects. According to the provisions of Chinese tender and bid law, for projects achieving a certain scale of construction, it regulates to adopt the bidding method and process to determine the most appropriate contractor without special reasons. Tendering and Bidding has no doubt played a significant role in the economic development of our country. However, with the rapid development of China's construction field, the irregularities in the bidding, such as rigging, collusion, secret operations, showed a rising trend, which greatly affected the fair competition of the construction market and hindered the healthy development of the construction industry. In the process of engineering construction, due to various subjective or objective reasons, the bidding activities can not play the effectiveness of optimal deal and allocation of resources, so as to make the bidding become the format, which is called the ineffective tendering in this paper.

In the analysis of the universality of the tender failure, the most prominent phenomenon is the dishonesty of the main body of the bidding. The subject of bidding market refers to all the "human" factors in the bidding activities, including the "stakeholders", such as the tenderer, bidder, bid evaluation and market supervision ". The supervision and constraints of their behaviors, to a large extent, determines the failure or success of the bidding activity itself.

\section{Conception and Review of Construction Ineffective Bidding}

In an ideal bidding activity, the legislature responsibility is clear and justice of legislation is fair with provisions of the perfect supervision system; perfect bidding procedures are set up to ensure fair and open bidding smoothly. It also provides supervision service in accordance with the legislative responsibilities, to ensure that the bidding and approval procedures open, fair and transparent, the 
tenderee and tendering agent proceeds in a specified time with best applicants principals; the bidding committee shall conform to the principals of fairness, openness an impartiality; bidders are committed to cost reduction and quality improvement to win the bid by the strength of the company. However, in many situations, the fact is not the case.

Construction ineffective bidding refers to the construction process cannot play its roles of preferred transaction and the effective allocation of resources due to subjective or objective reasons in the bidding activities, so as to make the bidding become a form. While in the engineering construction bidding failure situation, human factors caused by the bidding rigging, affiliation, subcontracting is one of the most prominent problems. JianZhong Xia in his paper summarize the ineffective bidding as the interests of the bidding stakeholders through a variety of means to cause ineffective invitation in the bidding process. In this paper, there are the following forms of ineffective bidding in construction engineering project:

1) Abortive tender due to lack of information dissemination of human-caused barriers.

2) Limit or exclude local or system tender, and protect local interests.

3) The quality of the bidding text leads to winning bid can not meet the requirements of the project and produce a large number of visa, compensation.

4) The tenderee, bidding agency, bidders collude and reveal the bid to the bidders.

6) The bidder get high compensation through on-site visa and other illegal means by concluding with the owners.

7) The tenderer or bidding agency get the information of bidders in advance and collude with certain bidders before the bidding, manipulate the quoting price by driving it up or down and decide the winning bidder internally.

8) The bidders surround the bidding and make commitment to win the bid in turns to reach common rigging of different projects.

9) Construction enterprises, outsourcing team and the owners collude together; outsourcing team affiliate to the construction corporation and conspired; construction enterprises and bidding agencies collude and make illegal operations.

10) Government departments set up administrative licensing matters to deprive the rights of the parties bidding illegally, or to intervene in the tendering and bidding activities by wantonly charges to the market.

11) Other various factors cause the tender price, the quality of the tender can not achieve the desired performance .

As can be seen from above, which leads to failure of bidding include objective factors, but mostly include man-made factors. This paper called dishonesty behaviors of main bodies with the outstanding phenomena of supervision dishonesty behaviors and rigging colluding behaviors.

\section{Empirical Analysis of Market Subjects Dishonesty Behaviors in Construction Bidding Field}

The subject of the bidding market includes the tenderee, the tendering agents, the bidders and the bidding evaluation committee. The moral risk factors can be divided into three types: Collusion between the tenderee and bidders, between the tendering agency and the tenderee or the bidder, and among bidders collusion. The tenderee is the source of public construction procurement and the soul of the role. The tenderee is usually with dominated role and position in government agencies, business and cultural institutions, large listed companies, joint ventures or multinational companies, who has greater voice and fare right, also has the administrative power of the government department, which easily affect the openness, fairness of the bidding process. In the practical process of bidding failure, the tenderer collusion manipulates high successful rates, which is also the research emphasis. The tenderee dishonesty behaviors usually include the dodging tenders, bidding collusion, false bid, works out the contraction contracts and etc.

[case1] On October 2008, in a Shanghai state owned enterprise construction projects, the identity of the experts should be kept confidential in accordance with the regulations, but the state-owned 
group convened a meeting of the evaluators before the evaluation and carried out the instructions of the leadership... .

[case 2] In 2011, A famous Beijing university prepared for renovation of the building in the Department of precision instruments. Before public biding, one of the stakeholders who participated in the discussion of the conference revealed the bid to a local decoration company and the company win the bid finally.

In case 1 , the bid evaluation committee manipulated by the tenderee issued tendentious opinions, so as to make certain bidders. Case 2 is the "bid leak", namely the bid is leaked ahead of the bidding activities to make certain bidder.

In fact, in the engineering construction bidding, there are lots of situations before the bidding activities, the bidding winner has been confirmed secretly in advance. While the tenderee still issue the bidding documents and request tendering agent or the bid evaluation committee that the bidder must be specific, thus it will appear with false tender. In this situation, the bidding process is just the format.

Related to the specific dishonesty behaviors of bidders, mainly include bidding rigging and collusion, affiliation, subcontracting and etc. Bidding rigging and bidding affiliation have a certain universality and a higher probability of occurrence with great potential loss. The following is the empirical analysis of the most common bidding rigging and collusion.

[Case 3]A budget of about RMB100million municipal engineering investment of $\mathrm{X}$ city is issued for bidding. There are 20 bidders after the pre-qualification evaluation. Bidders A successfully colluded with other companies, and distribute some benefits as a deposit of accompany fee, and then carry out the unified arrangement of the tender offer. At that time, the normal price of the project with the competitive quotation and reasonable settlement is RMB80million, but through a massive rigging and collusion, the price was raised $10-20 \%$, is RMB95million. Then RMB10million of the the more 15 million was allocated among the accompany parties.

The above is a typical case of rigging and collusion, and the scale has reached large collusion. For the real bidding activities, generally there are two kind of bidding rigging behaviors: (1) horizontal collusion among the bidders; (2) vertical collusion among the tenderee and bidder or bidding agency. Collusion is a kind of horizontal collusion, refers to a certain scale of the collusion between a coalition of interests, through the manipulation of the tender offer, to the exclusion of other bidders, so as to control the bid winning prices and results. The general performance of the mutual agreement is that several bidders agree to raise or depress bidding price between each other, respectively with high, medium and low bid offer. Or the bidders first proceed with internal auction and decide the winner secretly so as to restrict competition and crowd out other bidders to make profits.

Government supervision dishonesty refers to the dishonesty behaviors due to the moral risk of the government related interest parties during bidding process.

[Case 4] A subway project of XX province issued the bidding for water treatment projects. After the enrolling in the pre qualification, the 6 finalists attend the final bidding, which accounted for $60 \%$ as economical standard and $40 \%$ for technology standard. The second of the economic standard win the bid with the price of nearly RMB1million higher than the first economic bigger (Total bid 7 million). The first refused to accept and complained, but subjected to the supervisions inaction and the warning to the Second, finally reluctantly withdraw.

It is obvious that the government supervision authorities do not act according to its responsibility which leading to dishonesty. At present, the problems of government authorities mainly include: the regulating authorities set up industry qualifications privately and thus cause the industry threshold, poor supervision, set the identity both for athletes and referees, and so on.

\section{Game Theory Model Analysis of the Typical Dishonesty Behaviors in Ineffective Bidding}

As stated above, the most typical problems in the ineffective bidding is the bidding collusion and rigging. Following, this paper will set up the game theory model and make the analysis. 
Take $\mathrm{n}$ as the bidder numbers, $\mathrm{c}$ as the cost, $\mathrm{b}$ as the normal price, $\mathrm{b}$ ' as the offer for bid rigging, $\mathrm{b}$ for horizontal accompany fee and $b$ "' for the vertical collusion fee, e for the extra income . Normal bid acceptance probability is taken as P and the probability as P1 for surround-bidding and P2 for vertical bidding collusion. The probability of being investigated is taken as $\mathrm{p}^{\prime}$ and the fine as $\mathrm{f}$. If being reported successfully by conspirators, the fine is $\mathrm{f}^{\prime}$ and the reporting probability is $\mathrm{p}$ " and double of the fine $2 \mathrm{f}^{\prime}$ to the prosecutor. All bidders, tenderer and accompanying bidders are neutral people and choose the prior probability of bid rigging was 0.5

1) For the normal offer, the expected return of the bidder $i$

$$
E(u i)=(b i-c i) \times P
$$

2) If bidder i decides for surrounding bidding

$$
E^{\prime}(u i)=\left(b^{\prime} i-c i\right) \times P 1-b^{\prime \prime} i-f \times p^{\prime}-f^{\prime} \times p^{\prime \prime}
$$

3) The expected return of accompanying bidder $k$ if he agrees to accompany the bidding with surround-bidding numbers is $\mathrm{m}$,

$$
E^{\prime}(u k)=\frac{b^{\prime \prime}}{m} \times P 1
$$

4) if reporting $\mathrm{i}$, the expected return of accompanying bidder $\mathrm{k}$

$E(u k)=(b k-c k) \times P+2 f^{\prime} \times p^{\prime \prime}$

5) the expected return of the bidder i for collusion

$E^{\prime \prime}(u i)=(b i-c i) \times P 2-b^{\prime \prime} i+e i-f \times p^{\prime}-f^{\prime} \times p^{\prime \prime}$

6) the expected return of the tenderee for normal bidding

$E(u z)=0$

7) the expected return of the tenderee for vertical collusion

$E^{\prime}(u z)=b^{\prime \prime \prime}-f \times p^{\prime}-f^{\prime} \times p^{\prime \prime}$

8 ) Bidding rigging model: $\mathrm{P}$ for participation, NP for not participating.

9) Bidder i decides to initiate surroundding based on $E^{\prime}(u i) \geq E(u i)$, it is

$\left(b^{\prime} i-c i\right) \times P 1-b^{\prime \prime} i-f \times p^{\prime}-f^{\prime} \times p^{\prime \prime} \geq(b i-c i) \times P$

10) Accompany bidder $\mathrm{k}$ agrees to participate the bidding rigging based on $E^{\prime}(u k) \geq E(u k)$, it is

$\frac{b^{\prime \prime}}{m} \times P 1 \geq(b k-c k) \times P+2 f^{\prime} \times p^{\prime \prime}$

11 ) bidder i decides for vertical collusion based on $E^{\prime \prime}(u i) \geq E(u i)$, so the formula is

$$
\left(b^{\prime \prime} i-c i\right) \times P 2+e i-b^{\prime \prime} i-f \times p^{\prime}-f^{\prime} \times p^{\prime \prime} \geq(b i-c i) \times P
$$

In horizontal bidding rigging, $P 1=\frac{1}{n-m+1}$. It can be seen if $\mathrm{n}$ is large enough, value of $\mathrm{P} 1$ would be low. While if $\mathrm{m}$ is large and near to $\mathrm{n}$, the value of $\mathrm{P} 1$ is nearly 1 . That is, if $\mathrm{m}$ is large enough, the bidders tenders to choose bidding rigging, while $\mathrm{n}$ is large enough, the probability of bidding rigging is low.

Under the normal lowest price bidding rules, $P 2=P$, and $b^{\prime \prime} i=b i$ then in formula 11) is: $e i-b^{\prime \prime \prime} i-f \times p^{\prime}-2 f^{\prime} \times p^{\prime \prime} \geq 0$. Then if bidder i cannot get high compensation after winning the bid with lowest quotation, he wouldn't quote abnormal low price during the bidding. Thus it can be seen if the bidder numbers is large enough, the successful probability of bidding rigging and collusion is low.

\section{Summary}

In the analysis of the universality of the bidding failure, the most prominent phenomenon is the main body dishonesty. Through the introduction of the actual case, this article analyzes the model and motivation of market objectives including the tenderee, bidders, government supervision authorities 
and the evaluation committees. Through the above empirical analysis, lack of social integrity and weak external supervision and punishment is the fundamental reason of frequent dishonesty behaviors. For the serious problem of bidding rigging, establish the game theory model. Finally, this article give suggests that establishing the credit evaluation mechanism, strengthening the information disclosure, introducing bidding supervision and report incentive mechanism can help to reduce the bidding riggings. From the angle of multi-period dynamic game theory, it also help to weaken the preference of bidding rigging and reverse the social atmosphere so that bidding system can play better for the role of effective allocation of social resources.

\section{References}

[1] Stigler.A Theory of Oligopoly, Journal of Political Economy, 72 (1964) 44-61.

[2] ZhuRong Cui. Application of game theory in the management of bid rigging, Economic Research Guide 28 (2012) 210-212.

[3] Eric Rasmusen. Games and information-An introduction game theory second edition. The Peking University Publishing House, SDX Joint Publishing Company,(2003).

[4] Y.K Che, J. Kim., Optimal collusion-proof auctions, Journal of Economic Theory, 144 (2009) 565-603.

[5]JianZhong Xia, Study of Problems Causing Ineffective Invitation for Tendering and Countermeasures for Management and Control in Government Procurement Projects. Application for Tsinghua University professional degree of Master of Engineering (2011).

[6] Casey B J,Shaffer L R. An evaluation of some competitive bidding stuategy models for contractors. Civil Engineering Studies. Construction Research Series No.4, University of Ilinois, Urbana, I11, (1964)

[7] M. Robinson, Collusion and the choice of auction, The RAND Journa of Economics, 16(1985)141-145.

[8] M. Marzouk and O. Moselhi, A decision support tool for construction bidding, Construction Innovation, 3(2003) 111-124. 